\title{
A Comparative Study of the Effect of Computer-based Instruction and Problem-solving Instruction on the Students' Creativity
}

\author{
Adnan Eshrati Fard ${ }^{1}$, Ali Asgary ${ }^{1}$, Gholam Reza Sarami ${ }^{1}, \&$ Akram Zarekar ${ }^{2}$ \\ ${ }^{1}$ Department of Education psychology, Kharazmi University, Tehran, Iran \\ ${ }^{2}$ Department of Clinical psychology, Islamic Azad University, Save, Iran \\ Correspondence: Adnan Eshrati Fard, Department of Education psychology, Kharazmi University, Tehran, Iran.
}

\author{
Received: July 15, 2013 Accepted: December 11, 2013 Online Published: January 24, 2014 \\ doi:10.11114/jets.v2i2.179 URL: http://dx.doi.org/10.11114/jets.v2i2.179
}

\begin{abstract}
The current study aimed to identify the appropriate method of teaching creativity through comparing computer-based instruction with problem-solving instruction. A sample of 50 male students studying in the second grade of junior high school was chosen and divided into two equal groups. Both groups filled out the Torrance Test of Creative Thinking (TTCT) in pre- and post-test stages. They also completed the Raven Standard Progressive Matrices (RSPM) as a covariate variable. The results of covariance analysis revealed that the mean value for creativity score was higher for the students provided with the computer-based method of instruction than that of their counterparts provided with the problem-solving method of instruction while the effect of intelligence was controlled. The scores obtained for the fluency component of creativity and those for flexibility, originality, and elaboration components also increased more through problem-solving and computer-based method of instruction, respectively. To sum up, employing computer-based method of instruction resulted in a further increase in the students' creativity.
\end{abstract}

Key words: Creativity, Computer-based instruction, Problem-solving method of instruction, Students

\section{Introduction}

Creativity as a complicated concept is unique considering its numerous definitions and reliable viewpoints. Having more than one definition, by itself, indicates the complexity of the concept (Jackson et al., 2012). Guilford (Stojanova, 2010) points to it as a divergent thinking in problem-solving which entails fluency, flexibility, originality and elaboration. In oxford Dictionary, creativity was defined as thinking about the problems through applying innovative ways and ideas (Fatemi, Hamidi, \& Rahimi, 2011).

A large body of research has focused on identifying the factors which might make an impact on it. One set of studies have tried to cast further light on the individual factors (e.g., personal characteristics, motivation, intelligence, gender, and cognitive styles). A second set of studies have dealt with the environmental ones (e.g., social, economic, cultural and educational factors). Nevertheless, among the second set of factors, the role of educational organizations seems to be of utmost significance (Furnham et al., 2008; Kletke, 2001; Stojanova, 2010).

In advanced educational systems, there are various instructional methods based on theories of creativity and its practical aspects, which contribute to its development. These methods mainly fall into two categories. In the first category, high emphasis is put on modern technologies (e.g., cell phone, video games and computer in education). Here, computer-based instruction would more likely lead to an increase in individuals' creativity than the other ones (Gudanescu, 2010; Kletke, 2001). The second category, known as creative techniques, includes brainstorming (freedom of ideas and absence of criticism), Cynectics or innovation (coordinating several issues in a new framework or structure), obligatory communication (relating two ideas or things which are, by no means, related) and problem-solving (Samkhaniyan, 2008). Creative techniques mostly emphasize on the active role of the receiver, enhancement of self-confidence and creation of different ideas. It seems that problem-solving is more fruitful than the other techniques in the latter category as the ideas would be presented in a goal-oriented and systematic way and the number of ineffective solutions would decrease (Barak \& Mesika, 2007).

In computer-based instruction, students take on active roles and enjoy higher degrees of motivation. Moreover, learning is more meaningful and the students' mental and visual structures are stimulated. It also involves them in solving the 
abstract problems and completing creative assignments (Celikler \& Aksan, 2011). This method, however, suffers from some shortcomings (e.g., lack of capability to establish humanistic and emotional relationship with the students). Furthermore, its money-consuming nature makes it difficult to be applied in a number of societies due to their economic problems (Ghezelbash et al., 2008; Jackson et al., 2008). Nevertheless, the primary evidence indicates that computer systems are considered as a technique for increasing creativity which has recently attracted the scholars' attention (Edmonds \& Candy, 2005).

Problem-solving skill, falling in the second category of the methods for developing creativity, is considered as an integral part of thinking and consists of several systematic stages. Problem-solving skill differs from solving a problem through several ways (e.g., computer). Problem-solving skill is a method which comprises of several stages. The students who learn the problem-solving process can succeed in each and every stage of their life and even solve the problems they have not encountered yet (Armagan, Sagir, \& Celik, 2009).

Kandemir and Gur (2009) believe that teaching the problem-solving skill to the students would lead to an increase in their creativity which in turn would enhance their academic achievement. However, this method is faced with some difficulties which might hinder its effective application in education. Lack of sufficient capability to define the problem, drawing sweeping conclusions and carrying high stress are among the most important difficulties (Seif, 2008). Although problem-solving involves some difficulties, it is conceived of as one of the most crucial creativity techniques. Hence, it seems that computer-based instruction and problem-solving instruction are among the most efficient, creative methodologies.

Although computer-based instruction and problem-solving instruction belong to different categories of creativity instruction, they bear some similarities. Both types of instruction, "for example", lead to the enhancement of the creative and abstract thinking and put high emphasis on presenting innovative solutions by the students, result in the promotion of presenting uncommon and new solutions, assign active roles to the students, make learning more meaningful and increase the students' motivation. However, the fundamental discrepancies between these two methods would bring about different results. "For instance", in problem-solving instruction, the social-emotional relationship between the teacher and the students and among the students would enhance while this is totally absent in computer-based instruction. Problem-solving method of instruction entails a number of systematic stages which includes specific steps based on which the instruction is presented. Hence, the focus of this method is on reaching a solution by going through these systematic stages. Computer-based instruction, on the contrary, is not systematic and the students are not required to taking any particular steps. In the former one, the teacher makes the students provide various solutions for a problem although all the answers might not be correct. In other words, this method puts higher emphasis on creating a large number of thoughts at a time while the latter one pays less attention to this point and more emphasis is put on the innovative and uncommon questions and answers, instead. However, problem-solving method of instruction takes more time while computer-based instruction is time-saving (Armagan, Sagir, \& Celik, 2009; celikler \& Aksan, 2011; Chang, Sung, Chen, \& Huang, 2008; Chen, 2010; Lubart, 2005; Treffinger, Selby, \& Isaksen, 2008).

Bearing this in mind, both methods have a number of commonalities and discrepancies, assets and flaws. The results of a large body of research (Barak \& Mesika 2007; celikler \& Aksan, 2011; Fatemi, Hamidi, \& Rahimi, 2011; Kandemir \& Gur, 2009 ; Kletke, 2001; Yuku, Harter, Liu, Thompson,\& Cheng, 2007) have revealed that these two methods, among two sets of creative technologies and techniques, play a contributing role in increasing the students' creativity. However, no study has so far been conducted to compare them. It is not systematically clear that which method could contribute more to an increase in the students' creativity.

On the other hand, although numerous studies have investigated the influence of computer-based instruction or problem-solving instruction on creativity, less attention has been allocated to some other influential factors. Here, an important question might arise that whether an increase in creativity was necessarily as a result of employing one of these methods or contribution of some other factors. A number of scholars (Batey, Furnham, \& Safiullina, 2010) maintained that the most appropriate way to investigate creativity is the one which considers the role of various factors simultaneously. In this regard, it seems that personal characteristics, knowledge, motivation, intelligence and gender are considered as the main influential ones (Furnham et al., 2008).

Intelligence is a crucial variable which makes an impact on creativity, problem-solving and computer. In other words, it is intertwined with creativity,( i.e., a certain extent of intelligence is required for creativity) (Furnham \& Bachtair, 2008). On the other hand, one variable which has received less attention in the creativity domain, while having a pivotal role in the relationship between the method of instruction and creativity, is the students' gender. Gender differences as an influential factor in computer-based instruction have been largely studied. One set of studies has given attention to the degree of acceptance and understanding of computer-based instruction among both male and female students and found mixed results. For example, the findings of a number of studies have revealed that men have much more positive 
understanding of the computer-based instruction compared to women (Conti, Collins, \& Picariello, 2001). Accordingly, considering the effect of intelligence and gender on the relationship between creativity and instruction, the current study strived to obtain more precise results through controlling these two variables.

With this in mind, the main interest of the study was to compare the effect of computer-based instruction and problem-solving instruction on the enhancement and increase of the students' creativity. To this end, the study specifically addressed the following two questions:

1) Which instructional method would contribute more to an increase in the students' creativity, computer-based instruction or problem-solving instruction?

2) Which instructional method would increase the fluency, flexibility, originality and elaboration characteristics, computer-based instruction or problem-solving instruction?

\section{Method}

\subsection{Participants}

A sample of 50 guidance school students with the average age range of 13.50 participated in this study. They were assigned to two groups of equal size. The study was conducted in the academic year 2013-2014. In order to control the possible impact of gender on creativity and instructional method, only male students were included in the sample.

\subsection{Instruments}

\subsubsection{The Torrance test of creative thinking (TTCT)}

The questionnaire was devised by Torrance (1974) underlying Guilford Intelligence theory. He designed a series of tests for creativity including two verbal tests (parallel forms of A \& B) and two pictorial tests (parallel forms of A \& B) (Seif, 2008). In the study, the B form of pictorial test for adults (over 12 years old) was utilized. The test can be administered both individually and cooperatively. It includes three activities which take almost 30 minutes (10 minutes for each activity). According to technical guide and scoring style of Torrance (1974), in pictorial form, like the verbal one, no emphasis is put on misspelling, shortage of vocabulary in evaluation and drawing skill. The criterion for evaluation is the presence of creative ideas in the form of a picture rather than the quality of the drawing. Hence, the presence of every individual sign which indicates creative thinking is considered in evaluation. As a result, even if the person enjoys a scant degree of drawing skill, s/he can perform moderately or well in the pictorial form. At the end of each activity, the person is asked to determine a title or to develop a story for his/her drawing in order to better clarify the pictorial idea. Torrance (1990) reported the calculated reliability of 0.88 to 0.96 for pictorial tests and 0.94 to 0.99 for verbal tests. The reliability obtained in through Cronbach alpha in this study was 0.84 . The validity of this test was also approved by the expert judgments.

\subsubsection{Raven Standard Progressive Matrices (RSPM)}

This test was designed by Raven (1958) and is considered as one of the most popular and applicable tests of intelligence which is utilized to measure people's general IQ. There are a host of reasons for this test being popular: it is easy to be administered, it can be administered both individually and cooperatively, it is culture-independent, and applicable for all age groups (Pind, Gunnarsdottir, \& Johannesson, 2003). This test includes 60 pictures, one part of each is missing and the testee should find the missing part among six or eight different alternatives. The test items are divided into five groups so that each of them includes 12 items whose difficulty level is gradually increasing (Schweizer, Goldhammer, Rauch, \& Moosbrugger, 2007). It takes 45 minutes and for each correct picture, one point is assigned. The maximum score for each testee will be 60 . Then, taking the raw score and the age of the testee into account, the equivalent intelligence score in intelligence table is determined. Barak (1972) obtained the Cronbach reliability coefficient of 0.96 and validity index of 0.57 for the RSPM (Williams \& Mccord, 2007). The reliability obtained in through Cronbach alpha in this study was 0.87 .

\subsubsection{Math Instruction Software}

In order to teach math through computer, the software was designed as follows:

1. Taking into account the instructional objectives of the coursebook and the creative methodology, a set of objectives was set.

2. Considering the objectives in stage 1, the software was designed.

3. The software included two sections: text and exercise. In the text section, some explanations were presented for each topic and the main points and characteristics were provided. Some examples were then given. In the exercise section, the software was designed keeping the following points into account:

1) The students could not move to another topic unless learning of the current topic was completed. 
2) The students could take on active roles since the software was designed so that the teacher's assistance was not required.

3) The software had high interactive capability. The exercises and examples were in multiple-choice and essay type formats and the students were provided with feedback following their answers.

4) The method of providing feedback was appropriate in that if the student's answer was correct, the rewarding words were provided and if the student's answer was wrong, s/he was directed toward re-studying while the reason was pinpointed. S/he then could answer the question again. The process would continue till the student could provide the correct answer (if the student was not able to answer correctly, the teacher could intervene).

5) The questions of the exercise would encourage the students to ponder.

\subsubsection{Polya's Pattern of Problem-solving Method of Instruction}

In order to provide problem-solving instruction, Polya's (1957) pattern was utilized. It entails four stages: 1. understanding the problem, 2. planning for the problem, 3. implementing the plan and selected solutions, 4. revision and control (Barak \& Mesika, 2007). In this study, the instruction was based on this pattern while taking the objectives (the objectives of both computer-based instruction and problem-solving instruction are the same) into account.

\subsection{Procedure}

Before presenting the instruction and in order to measure the students' primary creativity and intelligence, Torrance Creating Thinking test, form B (1974) and Raven Intelligence Test (1958) were administered, respectively. Math was taught through problem-solving method to one group and through computer-based method to the other one in 8 ninety-minute sessions. For computer-based instruction of math, the software was designed and for problem-solving instruction, Polya's (1957) pattern was utilized. The content presented through both methods was the same. When the instruction finished, the form B of the test was again administered to both groups. In the current study, the role of intelligence was controlled by considering the hypotheses behind applying Covariance analysis. It is worth mentioning that in order to control the role of gender, only male students were included in the sample.

\section{Results}

Table 1 summarizes the descriptive statistics (including mean and standard deviation) for the obtained data. In order to analyze the data, covariance analysis was run. Tables 2 and 3 illustrate the results.

Table 1. Mean and standard deviation for the factors for both groups

\begin{tabular}{|c|c|c|c|c|c|c|c|c|}
\hline \multirow{3}{*}{ Resources } & \multicolumn{4}{|c|}{ The group with computer-based instruction } & \multicolumn{4}{|c|}{ The group with problem-solving instruction } \\
\hline & \multicolumn{2}{|c|}{ Pre-test } & \multicolumn{2}{|c|}{ Post-test } & \multicolumn{2}{|c|}{ Pre-test } & \multicolumn{2}{|c|}{ Post-test } \\
\hline & $\mathrm{M}$ & SD & $\mathrm{M}$ & $\mathrm{SD}$ & $\mathrm{M}$ & $\mathrm{SD}$ & $\mathrm{M}$ & $\mathrm{SD}$ \\
\hline Creativity & 118.48 & 8.28 & 144.44 & 11.46 & 120.64 & 8.00 & 134.52 & 9.44 \\
\hline Fluency & 13.56 & 2.85 & 16.24 & 4.12 & 14.00 & 2.51 & 19.76 & 4.48 \\
\hline Flexibility & 15.04 & 3.16 & 19.92 & 4.41 & 15.40 & 2.91 & 17.40 & 3.25 \\
\hline Originality & 16.56 & 2.43 & 21.48 & 4.36 & 16.60 & 2.43 & 18.92 & 3.13 \\
\hline Elaboration & 73.32 & 5.99 & 86.13 & 6.30 & 74.68 & 5.97 & 78.42 & 5.04 \\
\hline Intelligence & 111.04 & 8.14 & & & 110.33 & 7.98 & & \\
\hline
\end{tabular}

Note: $\mathrm{M}=$ Mean, $\mathrm{S}=$ Standard Deviation

As Table 1 displays, the mean scores of the students' creativity in pre-test and post-test increased about 25.96 (118.48 vs. 144.44) in the group with computer-based instruction. It also shows that the scores of fluency, flexibility, originality and elaboration increased as a result of computer-based instruction. On the other hand, the mean scores of the students' creativity (about 13.88) and its components increased in the group with problem-solving instruction. The scores of the fluency, flexibility, originality and elaboration were also higher in post-test. Moreover, as Table 1 indicates, the mean of intelligence scores in the group with computer-based instruction (111.04) was not significantly different from those of the group with problem-solving instruction (110.33).

Question 1: Which instructional method would contribute more to an increase in the students' creativity, computer-based instruction or problem-solving instruction?

The relevant results are presented in Table 2. 
Table 2. A summary of covariance analysis for the total score of creativity taking intelligence and pre- test as the control variables

\begin{tabular}{lccccc}
\hline Resources & SS & DF & MS & F & P-value \\
\hline Creativity Pre-test & 434.30 & 1 & 434.30 & 22.68 & .01 \\
Intelligence & 585.09 & 1 & 585.09 & 30.56 & .01 \\
Group & 1345.38 & 1 & 1345.38 & 70.27 & .02 \\
Error & 823.23 & 43 & 19.14 & & \\
\hline
\end{tabular}

Note: $\mathrm{SS}=$ Sum of Squares, MS= Mean Square, Significance ${ }^{*} P<0.05$

As Table 2 illustrates, $F$ index for the group effect $(\mathrm{F}(1,43)=70.27)$ is statistically significant $(p<0.05)$.

Accordingly, it might be concluded that a significant difference exists among the creativity scores in terms of the group while intelligence and creativity pre-test are controlled for.

In addition, $\mathrm{F}$ indices for the effect of creativity pre-test $(\mathrm{F}(1,43)=22.68)$ is statistically significant $(p<0.05)$. In other words, both variables would make an impact on the creativity post-test and controlling them lead to a significant difference between the two groups in post-test.

According to Table 1, the mean score of creativity for the group with computer-based instruction is higher than that of the group with problem-solving instruction.

Question 2. Which instructional method would increase the fluency, flexibility, originality and elaboration characteristics, computer-based instruction or problem-solving instruction?

Table 3. A summary of covariance analysis for the post-test scores of fluency, flexibility, originality, and elaboration removing the effect of intelligence and pre-test scores for these components

\begin{tabular}{lccccc}
\hline Resources & SS & DF & MS & F & P-value \\
\hline Fluency Pre-test & & Fluency & & & \\
Intelligence & 236.81 & 1 & 236.81 & 74.41 & .01 \\
Group & 4.84 & 1 & 4.84 & 1.52 & .22 \\
Error & 102.29 & 1 & 102.29 & 32.14 & .01 \\
& 136.84 & 43 & 3.18 & & \\
Flexibility Pre-test & 221.43 & Flexibility & & & .01 \\
Intelligence & 11.29 & 1 & 221.43 & 67.42 & .07 \\
Group & 104.03 & 1 & 11.29 & 3.43 & .01 \\
Error & 141.23 & 43 & 104.03 & 31.67 & \\
& & 3.28 & & .01 \\
Originality Pre-test & 299.79 & Originality & & & .29 \\
Intelligence & 5.86 & 1 & 299.79 & 57.07 & .01 \\
Group & 85.42 & 1 & 5.86 & 1.11 & \\
Error & 225.85 & 43 & 85.42 & 16.26 & .01 \\
& & 5.25 & & .02 \\
Elaboration Pre-test & 770.17 & Elaboration & & & .01 \\
Intelligence & 66.16 & 1 & 770.17 & 63.42 & \\
Group & 850.19 & 1 & 66.16 & 5.44 & 70.00 \\
Error & 522.19 & 43 & 850.19 & & \\
\hline
\end{tabular}

Note: $\mathrm{SS}=$ Sum of Squares, MS $=$ Mean Square, Significance ${ }^{*} P<0.05$

As Table 3 indicates, $F$ for the group effect in fluency $(F(1,43)=32.14)$, flexibility $(F(1,43)=31.67)$, originality $(F$ $(1,43)=16.26)$, and elaboration $(\mathrm{F}(1,43)=70)$ is statistically significant $(p<0.05)$. Hence, it might be inferred that there is a significant difference among the scores of the creativity components in terms of the instructional method while the effect of intelligence and pre-tests for these components are controlled for.

According to Table 1, the highest mean score belongs to flexibility, originality and elaboration in the group with computer-based instruction while fluency has the highest mean score in the group with problem-solving instruction.

\section{Discussion}

The current study aimed at comparing the effect of computer-based method to that of problem-solving instruction of 
math on the male students' creativity while the effect of intelligence was controlled for. "Overall", the findings indicated that computer-based instruction would lead to higher degrees of creativity than problem-solving instruction. In this sense, the students who were presented with computer-based math instruction gained higher scores in the creativity test compared to those who were presented with problem-solving math instruction. To justify the results, we can refer to both theoretical and practical principles.

It seems that one contributing factor to an increase in creativity in computer-based instruction is the degree of freedom which the students might achieve (Kodak, Fisher, Clements, \& Boouxsein, 2011). This freedom may be expressed in several forms, (e.g., the instruction is presented at the learners' own learning rate, the students can work more on the areas of difficulties, they can refer to previous sections more easily in order to study more, they can make use of various ways to answer their questions and do their homework without any limitation). This would allow them to take advantage of innovative and creative ways to come up with the correct answer. Overall, freedom would increase the students' creativity scores. On the other hand, although problem-solving instruction provides students with freedom, due to more determining role of the teacher in this method, the extent of freedom is lower than that in computer-based instruction.

Another factor which plays a pivotal role in the computer-based instruction and creativity is the motivation, interest and positive enthusiasm which the students would develop in this method. As the instruction is presented through making use of natural pictures, attractive and appropriate colors, various and numerous materials and examples, on-time feedback throughout the teaching process and working with the computer, positive enthusiasm, interest and motivation for learning would increase and this, in turn, would lead to an increase in creativity (Kodak et al., 2011). On the other hand, it seems that problem-solving instruction builds up lower degrees of motivation as a result of utilizing less number of pictures and colors, less feedback and more lectures and lower degrees of students' participation which would lead to lower degrees of creativity.

The influence of computer-based instruction on the creativity score might be attributed to the students' active participation. Clement (2000) holds that computer-based instruction assigns the teacher the role of a guide who intervenes only when the students are faced with difficulties. Hence, the students should carry the main burden of instruction. Being active would lead to their more responsibility for taking on the roles and accepting the responsibilities for both success and failure and help them not to be inactive in the face of problems and search for various innovative solutions, instead. This would, in turn, increase the students' creative thinking. On the other hand, although the students are more active in problem-solving instruction than in traditional methods (Barak \& Mesika, 2007), it seems that the teacher still carries the major burden of instruction and does not provide the students with several opportunities for taking on more responsibilities compared to computer-based instruction. As a result, they might play a less active role in confronting with problems and thereby, look less for various innovative solutions.

The study also revealed that although the creativity score underwent more increase in the group with computer-based instruction, the fluency component and the flexibility, originality and elaboration components increased more in computer-based instruction and problem-solving instruction, respectively. The increase might be due to the importance of creating numerous thoughts at a time (Treffinger, Selby, \& Isaksen, 2008). Considering the second stage of teaching problem-solving pattern, planning the problem, the main point is pushing the students to present various solutions for a problem. The students should provide various solutions within a time limit regardless of their accuracy. This would encourage the students to seek more solutions in the face of various problems so that they have several alternatives (Palmon \& Illies, 2004). While providing a number of solutions within a time limit is considered as a core stage of problem-solving instruction (Kadivar, 2009), it seems that less attention is paid to leading the students toward systematic presentation of several thoughts within a time limit in computer-based instruction.

An increase in the flexibility component of creativity through computer-based instruction might result from the opportunity it provides for more practicing of the lessons so that the students can review the key points and enhance both their knowledge and skill. From Gudanescu's (2010) perspective, an increase in knowledge and skill in an area would result in the students' more abstract and creative thinking and making use of more uncommon solutions and thereby, would enhance their flexibility in the face of problems. On the other hand, it seems that problem-solving instruction enjoys less flexibility as it comprises of systematic stages based on which the instruction should be provided (Truxaw \& Defranco, 2007).

On the other hand, computer-based instruction focuses on individual instruction and each student answers various questions matched with his/her level of competence. Accordingly, creative and abstract exercises and items can be designed to provide them with an opportunity to take advantage of innovative and creative solutions (Celikler \& Aksan, 2011; Lubart, 2005). In contrast, problem-solving instruction provides less opportunity for designing such items since it is based on cooperative instruction and takes an average student into account. 
Another characteristic of computer-based instruction is presenting numerous examples and exercises and examining the underlying reason of the students' difficulty in solving the problem which would result in allocating more attention to analyzing the problem and its details. An increase in the score of elaboration component might be attributed to this characteristic (Bruning et al., 2008; Jackson et al., 2012). Contrarily, considering the fact that problem-solving instruction requires more time and provides the teacher with less opportunity to pay deserving attention to the problem details (Seif, 2008), the elaboration component is less influenced. On the other hand, unlike computer-based instruction which emphasizes on individual aspects and considers each student's level of learning competence and interest, assigns more exercises and pays more attention to details (Jackson et al., 2012), problem-solving instruction, with its focus on cooperative learning and problem details, might be boring for a number of students with cognitive, field-dependent style and general understanding of the problems (Kenneth, 2009) and might force the teacher to pay less attention to the problem details.

\section{Conclusion}

To put in a nutshell, it might be said that creativity and innovation play a key role in the growth and development of a society and thereby, seem worth being investigated. Hence, one of the most important goals of any educational system should be bringing up creative individuals who are able to make right decisions in unexpected situations. This would, by no means, be accomplished through traditional instruction and requires implementing innovative and creative techniques and methods in educational systems. These new techniques and methods would make different impacts on the extent to which creativity increases. Hence, it seems necessary to choose the most appropriate ones based on which the instruction is provided. Together, the findings of the current study might suggest that computer-based instruction would lead to more increase in the individual's creativity score through providing an attractive educational context, increasing the student's cooperation in the teaching process, providing more independence and freedom, building up and enhancing motivation and interest compared to problem-solving instruction. It is the hope of the researcher that the Ministry of Education sets the scene for implementing this method of instruction through equipping the schools with computerized systems so that the teachers would obtain the great bulk of knowledge and would overcome its flaws in order to apply it in their classes and provide a setting for increasing creativity and bringing up creative students, and consequently, a creative society.

\section{Acknowledgement}

We grab this opportunity to express my heartfelt thanks to Professor Parvin Kadivar for her insightful comments throughout conducting this study. We also thank the Education Organization for providing this opportunity for doing the project in schools.

\section{References}

Armagan, F. O., Sagır, A. U., \& Çelik, A. Y. (2009). The effects of students' problem solving skills on their understanding of chemical rate and their achievement on this issue. Procedia Social and Behavioral Sciences, 1 , 2678-2684. http://dx.doi.org/10.1016/j.sbspro.2009.01.473

Barak, M., \& Mesika, P. (2007). Teaching methods for inventive problem-solving in junior high school. Thinking skills and creativity, 2, 19-29. http://dx.doi.org/10.1016/j.tsc.2006.10.002

Batey, M., Furnham, A., Safiullina, X. (2010). Intelligence. general knowledge and personality as predictors of creativity. Learning and individual differences, 20, 532-535. http://dx.doi.org/10.1016/j.lindif.2010.04.008

Bruning, R., et al. (2008). Introducing teaching cases with face to face and computer mediated discussion: two multi-classroom quasi-experiments. Contemporary educational psychology, $33, \quad 299 \quad-\quad 326$. http://dx.doi.org/10.1016/j.cedpsych.2006.11.002

Celikler, D., \& Aksan, Z. (2011). The of computer assisted instruction in teaching ionic compounds on pre-service elementary science teachers academic achievement and permanent learning. Procedia Social and Behavioral Sciences, 28, 547-552. http://dx.doi.org/10.1016/j.sbspro.2011.11.105

Chang, K. E., Sung, Y. T., Chen, Y. L., \& Huang, L. H. (2008). Learning multiplication through computer-assisted learning activities. Computers in human behavior, 24, 2904-2916. http://dx.doi.org/10.1016/j.chb.2008.04.015

Chen, C. (2010). Teaching problem solving and database skills that transfer. Journal of Business Research, 63, 175-181. http://dx.doi.org/10.1016/j.jbusres.2009.03.005

Conti, R., Collins, M. A., Picariello, M. L. (2001). The impact of competition on intrinsic motivation and creativity: considering, gender, gender segregation and gender role orientation. Personality and Individual Differences, 30, 1273-1289. http://dx.doi.org/10.1016/S0191-8869(00)00217-8

Edmonds, E. A., \& Candy, L. (2005). The studio as laboratory: combining creative practice and digital technology 
research. Human-computer studies, 63, 452-481. http://dx.doi.org/10.1016/j.ijhcs.2005.04.012

Fatemi, M., Hamidi, F., Rahimi, M. (2011). The comparative effect of computer-aided instruction and traditional teaching on student's creativity I math classes. Procedia Computer Science, 3, 266-270. http://dx.doi.org/10.1016/j.procs.2010.12.045

Furnham, A., et al. (2008). Personality, hypomania, intelligence and creativity. Personality and Individual Differences, 44, 1060-1069. http://dx.doi.org/10.1016/j.paid.2007.10.035

Furnham, A., \& Bachtiar, V. (2008). Personality and intelligence as predictors of creativity. Personality and individual differences, 45, 613-617. http://dx.doi.org/10.1016/j.paid.2008.06.023

Ghezelbash. A., et al. (2008). Comparing the correct learning rate of electrocardiogram through using lecture-based, problem-solving, and computer-assisted self-study methods: The case of Nursing students. Iranian journal of Nursing Research, 3(7), 54-67.

Gudanescu, S. (2010). New educational technologies. Procedia Social and Behavioral Sciences, 2, 5646-5649. http://dx.doi.org/10.1016/j.sbspro.2010.03.922

Jackson, L. A., et al. (2012). Information technology use and creativity: finding s from the children and technology project. Computers in human behavior, 28, 370-376. http://dx.doi.org/10.1016/j.chb.2011.10.006

Jackson, L. A., et al. (2008). Culture, gender and information technology use: a comparison of Chinese and us children. Computers in human behavior, 24, 2817-2829. http://dx.doi.org/10.1016/j.chb.2008.04.007

Kadivar, P. (2009). Learning psychology. Tehran, Samt Publications.

Kandemir, M. A., \& Gür, A.(2009). The use of creative problem solving scenarios in mathematics education: views of some prospective teachers. Procedia Social and Behavioral Sciences, 1, 1628-1635. http://dx.doi.org/10.1016/j.sbspro.2009.01.286

Kenneth, H. S. (2009). The effect of computer-assisted instruction and field independence on the development of rhythm sight-reading skills of middle school instrumental student. International journal of music education, 27(7), 59-68.

Kletke, M. G. (2001). Creativity in the organization: the role of individual creative problem solving and computer support. Human-computer studies, 55, 217-237. http://dx.doi.org/10.1006/ijhc.2001.0467

Kodak, T., Fisher, W. W., Clements, A., \& Boouxsein, K. J. (2011). Effects of computer-assisted instruction on correct responding and procedural integrity during early intensive behavioral intervention. Research in autism spectrum disorders, 5, 640-647. http://dx.doi.org/10.1016/j.rasd.2010.07.011

Lubart, T. (2005). How can computers be partners in the creative process: classification and commentary on the special issue. Human-computer studies, 63, 365-369. http://dx.doi.org/10.1016/j.ijhcs.2005.04.002

Palmon, R. R., Illies, B, J. (2004). Leadership and creativity: Understanding leadership from creative problem-solving perspective. The Leadership Quarterly, 15, 55-77. http://dx.doi.org/10.1016/j.leaqua.2003.12.005

Pind, J., Gunnarsdottir, E. K., Johannesson, H. S .(2003). Raven's Standard Progressive Matrices: new school age norms and a study of the test's validity. Personality and Individual Differences, 34, 375-386. http://dx.doi.org/10.1016/S0191-8869(02)00058-2

Polya, G. (1957). How to solve it: A new aspect of mathematical method (2nd ed.). Princeton, NJ: Princeton University Press.

Raven, J. C. (1958). Standard progressive matrices. London: H.K. Lewis.

Samkhaniyan. M. (2008). Creativity and innovation in educational system. Tehran, Specialized Media Publications.

Schweizer, K., Goldhammer, F., Rauch, W., \& Moosbrugger, H. (2007). On the validity of Raven's matrices test: Does spatial ability contribute to performance?. Personality and Individual Differences, 43, 1998-2010. http://dx.doi.org/10.1016/j.paid.2007.06.008

Seif, A. (2008). Modern training psychology. Tehran, Doran Publications.

Stojanova, B. (2010). Development of creativity as a basic task of the modern educational system. Procedia Social and Behavioral Sciences, 2, 3395-3400. http://dx.doi.org/10.1016/j.sbspro.2010.03.522

Torrance, E. P. (1974). Norms-Technical Manual Torrance test of creative thinking. Verbal Test Forms A and B. Figural test Forms $A$ and $B$. Personal Press Inc.

Torrance, E. P. (1990). Torrance tests of creative thinking: Manual for scoring and interpreting results(Verbal. Forms A 
and B). Bensenville, IL: Scholastic Testing Service.

Treffinger, D. J., Selby, E. C., Isaksen. (2008). Understanding individual problem-solving style: A key to learning applying creative problem solving. Learning and Individual Differences, 18, 390-401. http://dx.doi.org/10.1016/j.lindif.2007.11.007

Truxaw, M. P., \& Defranco, T. C. (2007). Mathematics in the making: Mapping verbal discourse in Polya's "Let Us Teach Guessing" lesson. Journal of Mathematical Behavior, 26, 96-114. http://dx.doi.org/10.1016/j.jmathb.2007.05.002

Williams, J. E., \& Mccord, D. M. (2006). Equivalence of standard and computerized versions of the Raven Progres sive Matrices Test. Computers in Human Behavior, 22, 791-800. http://dx.doi.org/10.1016/j.chb.2004.03.005

Yuku, H., Harter, C. A., Liu, F. L., Thompson, L., \& Cheng, Y. C. (2007). The effects of individually personalized computer - based instructional program on solving mathematics problems. Computers in human behavior, 23, 1195-1210. http://dx.doi.org/10.1016/j.chb.2004.11.017

\section{(cc) $\mathrm{EY}$}

This work is licensed under a Creative Commons Attribution 3.0 License. 